\title{
Immunohistochemical expression of nestin in rhabdomyosarcoma: implications for clinicopathology and patient outcome
}

\author{
S. Glumac ${ }^{1}$, S. Pejic ${ }^{2}$, R. Kovacevic ${ }^{1}$, D. Dundjerovic ${ }^{1}$, R. Davidovic ${ }^{3}$, D. Ristic ${ }^{4}$ \\ and J. Sopta ${ }^{1}$ \\ ${ }^{1}$ Institute of Pathology, School of Medicine, University of Belgrade, Serbia \\ 'Laboratory for Molecular Biology and Endocrinology, \\ "Vinča" Institute of Nuclear Sciences, University of Belgrade, Belgrade, Serbia \\ ${ }^{3}$ Department for Radiobiology and Molecular Genetics, \\ "Vinča" Institute of Nuclear Sciences, University of Belgrade, Belgrade, Serbia \\ ${ }^{4}$ Institute for Oncology and Radiology of Serbia, Belgrade, Serbia \\ Corresponding author: S. Glumac \\ E-mail: sofijaglumac09@gmail.com \\ Genet. Mol. Res. 14 (4): 14649-14659 (2015) \\ Received August 24, 2015 \\ Accepted November 4, 2015 \\ Published November 18, 2015 \\ DOI http://dx.doi.org/10.4238/2015.November.18.29
}

ABSTRACT. Rhabdomyosarcoma (RMS) is a highly malignant cancer. Over the last two decades, prognosis for RMS patients has significantly improved, with the exception of those in the high-risk group. In order to identify new prognostic factors, we investigated the expression of nestin in RMS cells and its correlation with clinicopathological features and patient outcome. The analysis of overall survival for all patients $(\mathrm{N}=30)$ revealed 1-, 2-, 3-, 4-, and 5-year survival rates of 93.3, 83.3, 66.7, 63.3, and $63.3 \%$, respectively. Nestin overexpression significantly correlated with survival $(P$ $=0.044)$. Survival of patients with $\leq 50 \%$ nestin-positive cells was 90,70 , and $40 \%$ after 1,2 , and 3 years, respectively, and remained unchanged until the end of the investigation period. The study group composed of patients exhibiting nestin expression in $>50 \%$ of cells showed 1-, 2-, 3-, and 4 -year survival rates of $95,90,80$, and $75 \%$, respectively, remaining 
stable at $75 \%$ for the fifth year of observation. A nestin-positive expression rate lower than $50 \%$ was observed more frequently in older patients (43.60 \pm 27.58 years; $P=0.028$ ). In addition, higher rates of nestin expression were observed in most embryonal RMS specimens and low-grade tumors, in early stages of the disease, and among younger patients. Our results lead us to propose nestin as possible positive prognostic factor in RMS.

Key words: Immunohistochemistry; Nestin; Rhabdomyosarcoma; Survival; Clinicopathological significance

\section{INTRODUCTION}

Rhabdomyosarcoma (RMS) is malignant tumor comprised of neoplastic cells with evidence of skeletal muscle differentiation. RMS is the most common soft tissue sarcoma in childhood, accounting for $5-10 \%$ of all pediatric malignancies (Dasgupta and Rodeberg, 2012). Based on histological and molecular features, the current World Health Organization classification categorizes RMS into three main subtypes: embryonal (encompassing botryoid, spindle cell, and anaplastic variants), alveolar (including the solid variant), and pleomorphic.

As with other soft tissue tumors (Almeida et al., 2008), outcome of RMS can be predicted according to prognostic factors. Based on such established factors (anatomic site, tumor-nodemetastasis status, and extent of disease after surgical resection), patients are divided into low-, intermediate-, and high-risk groups (Dasgupta and Rodeberg, 2012; Parham et al., 2013).

These categories are associated with distinct clinical outcomes. Active research over the past two decades has changed the prognosis of RMS. At present, more than $90 \%$ of patients in the low-risk group will be cured, however, overall survival (OS) is low for patients with high-risk RMS, and has not improved (Meza et al., 2006; Dasgupta and Rodeberg, 2012). Prognosis is linked not only to disease stage, but also to the aggressiveness of individual malignancies, which is characterized by high potential for metastasis and resistance to antitumor therapy (Meza et al., 2006). To identify factors that contribute to poor RMS prognosis, researchers have studied many potentially associated molecular markers.

Nestin, a class VI intermediate filament protein, is expressed in a number of cell types, including neural crest and skeletal muscle progenitor cells (Lendahl et al., 1990; Pallari et al., 2011). Initially regarded as a marker of neural stem cells, it has subsequently been established that nestin is abundantly expressed in embryonic stem cells. In adults, nestin is only found in tissues under reactive conditions, such as those during glial scar formation following injury to the central nervous system, and during regeneration of injured skeletal muscle tissue (Wiese et al., 2004). Although the precise function of nestin remains to be elucidated, studies suggest that it may play a role in the control of cell proliferation, survival, and differentiation. This protein is also a putative marker of cancer stem cells (Yang et al., 2008), and recent studies have demonstrated that nestin levels in tumor cells correlate with the malignant grade and undifferentiated state of cancers including glioma, melanoma, RMS, gastrointestinal and testicular stromal tumors, and adrenocortical tumors (Yang et al., 2008; Krupkova et al., 2010).

Owing to its expression in many types of human solid tumors, nestin may also serve as a diagnostic and possibly prognostic marker of tumor malignancy. Detailed analyses of nestin expression patterns in various tumor tissues including RMS would be helpful to establish its role 
in mechanisms of tumor growth and invasion, and identify novel therapeutic targets. In this study, we investigated the expression of nestin in RMS cells by immunohistochemistry, and assessed its possible correlation with tumor prognosis.

\section{MATERIAL AND METHODS}

\section{Patients}

This study included 30 patients treated for RMS between 1995 and 2012. Records from the Soft Tissue and Bone Registry of the Institute of Pathology, Medical School, University of Belgrade, Serbia, were reviewed for all patients.

Histopathological diagnosis was made according to International Classification of Rhabdomyosarcoma criteria, in accordance with the Intergroup Rhabdomyosarcoma Study (IRS) Group (Newton et al., 1995). The following primary antibodies were used to confirm diagnoses: anti-desmin, anti-vimentin, anti-myogenin, AE1/AE3, and anti-INI-1. Histologically, tumors were divided into embryonal, alveolar, and pleomorphic subtypes. All 30 cases were reviewed and histological types confirmed by two of the authors (J.S. and S.G.).

Patient characteristics are summarized in Table 1. The majority of patients were men (63.3\%), with an average age of $29.14 \pm 25.84$ years (range $=0.8-77.0$ years, median $=18.5$ years) and most showed disseminated disease (60.0\%). The upper extremity was the most frequently observed disease site $(46.4 \%)$, and tumors $>5 \mathrm{~cm}$ were observed in $70.0 \%$ of patients. The most common histological subtype was embryonal (40.0\%). Low- and high-grade RMS were equally represented, and the follow-up period was 5 years (range $=10-60$ months). OS time was defined as the time between the date of diagnosis and the date of death. Patients still alive at the final follow-up date were censored.

\begin{tabular}{|c|c|}
\hline Characteristic & Value \\
\hline All patients, $\mathrm{N}$ & 30 \\
\hline \multicolumn{2}{|l|}{ Gender, N (\%) } \\
\hline Male & $19(63.3)$ \\
\hline Female & $11(36.7)$ \\
\hline Age, years (median; range) & $29.14 \pm 25.84(18.5 ; 0.8-77)$ \\
\hline \multicolumn{2}{|l|}{ Primary site, N (\%) } \\
\hline Upper extremity & $14(46,7)$ \\
\hline Lower extremity & $12(40.0)$ \\
\hline Trunk & $4(13.3)$ \\
\hline \multicolumn{2}{|l|}{ Histological type, N (\%) } \\
\hline Embryonal & $12(40.0)$ \\
\hline Alveolar & $10(33.3)$ \\
\hline Pleomorphic & $8(26.7)$ \\
\hline \multicolumn{2}{|l|}{ Metastasis N (\%) } \\
\hline Yes & $18(60.0)$ \\
\hline No & $12(40.0)$ \\
\hline \multicolumn{2}{|l|}{ Tumor size, N (\%) } \\
\hline$\leq 5 \mathrm{~cm}$ & $9(30.0)$ \\
\hline$>5 \mathrm{~cm}$ & $21(70.0)$ \\
\hline \multicolumn{2}{|l|}{ Grade, N (\%) } \\
\hline Low & $15(50.0)$ \\
\hline High & $15(50.0)$ \\
\hline \multicolumn{2}{|l|}{ Vital status, N (\%) } \\
\hline Alive & $19(63.3)$ \\
\hline Dead & $11(36.7)$ \\
\hline
\end{tabular}




\section{Immunohistochemical procedure}

Immunohistochemical analysis of nestin was performed on $5-\mu m$ tissue sections prepared from paraffin blocks. Sections (5- $\mu \mathrm{m}$ thick) from formalin-fixed, paraffin-embedded tissue samples were deparaffinized and treated with $3 \%$ hydrogen peroxide for 15 min to block endogenous peroxidase activity. Heat-induced antigen retrieval was carried out by immersing tissue sections in $0.01 \mathrm{M}$ citrate buffer, $\mathrm{pH} 6.0$, and heating them in a microwave oven for $20 \mathrm{~min}$ at $620 \mathrm{~W}$. After cooling off for $30 \mathrm{~min}$ at room temperature, blocking peptide (Dako, Glostrup, Denmark) was utilized to block non-specific staining. Tissue sections were then incubated overnight at $4^{\circ} \mathrm{C}$ with anti-nestin rabbit monoclonal primary antibody (clone SP103, 1:100 dilution; Abcam Inc., Cambridge, MA, USA). Using an LSAB+ kit (Dako), the streptavidin-biotin technique was applied, with diaminobenzidine as the chromogen solution and Mayer's hematoxylin as the counterstain. Human kidney tissue was included in every staining procedure as a positive control for nestin, while incubation with pure antibody diluent (without the primary antibody) served as a negative control.

Cytoplasmic expression of nestin was then determined. All immunostained sections were independently evaluated by two authors (J.S. and S.G.). Immunohistochemical staining results were scored using a semiquantitative technique according to the following categories: absence of staining in all tumor cells (negative staining; -); positive staining in less than $10 \%$ of cells (focal expression; +); $10-50 \%$ positive cells (moderate expression; ++); and more than $50 \%$ positive cells (diffuse expression; +++). For statistical analyses, cases showing negative or focal expression were grouped together, as were those with moderate or diffuse expression. These latter two categories were regarded as having $>50 \%$ nestin-positive tumor cells, and the former $\leq 50 \%$. Immunostaining intensity was also evaluated in endothelial cells, as an internal positive control.

\section{Statistical analysis}

Statistical analyses were performed with SPSS 18.0 for Windows (SPSS Inc., Chicago, IL, USA). At the beginning of the study, all variables were described using the classical methods of descriptive statistics (absolute and relative numbers). In order to test differences between parameters, the Pearson chi-square chi-square test was used. For each clinical and morphological variable, associations with vital status and overall survivalsurvival and OS were assessed by univariate analysis using the Kaplan-Meier method and log-rank test. Univariate and multivariate regression analyses were performed using the Cox proportional hazards regression model to analyze independent factors related to prognosis. $\mathrm{P}$ values $<0.05$ were considered significant.

\section{RESULTS}

The analysis of OS for all patients $(\mathrm{N}=30)$ revealed that $93.3,83.3,66.7$, and $63.3 \%$ of patients were alive after 1,2,3, and 4 years, respectively, and this proportion did not change during the fifth year of follow-up (Figure 1). Statistically significant correlation was found for survival and histological types of RMS $(P=0.004)$, tumor grade $(P=0.001)$ and nestin expression $(P=0.044)$ (Table 2). The highest survival rate was observed in the group of patients with embryonal type of RMS, in which none of whom died during the follow-up period (Figure 1). In the group of subjects with low-grade tumors, none of the patients died in the first two years of follow-up (Figure 1). 
The highest survival rate was observed in patients with embryonal RMS, none of whom died during the follow-up period $(\mathrm{P}=0.004)$. Survival of patients with alveolar RMS was $90 \%$ after 1 year, $80 \%$ after 2 years, $40 \%$ after 3 , and $30 \%$ after 4 , as it was after 5 years. Pleomorphic RMS patients showed survival rates of $87.5,62.5$, and $50 \%$ after 1,2 , and 3 years, respectively, and this proportion had not changed by the end of the follow-up period (Figure 1).

We found no significant association between other examined parameters and survival.
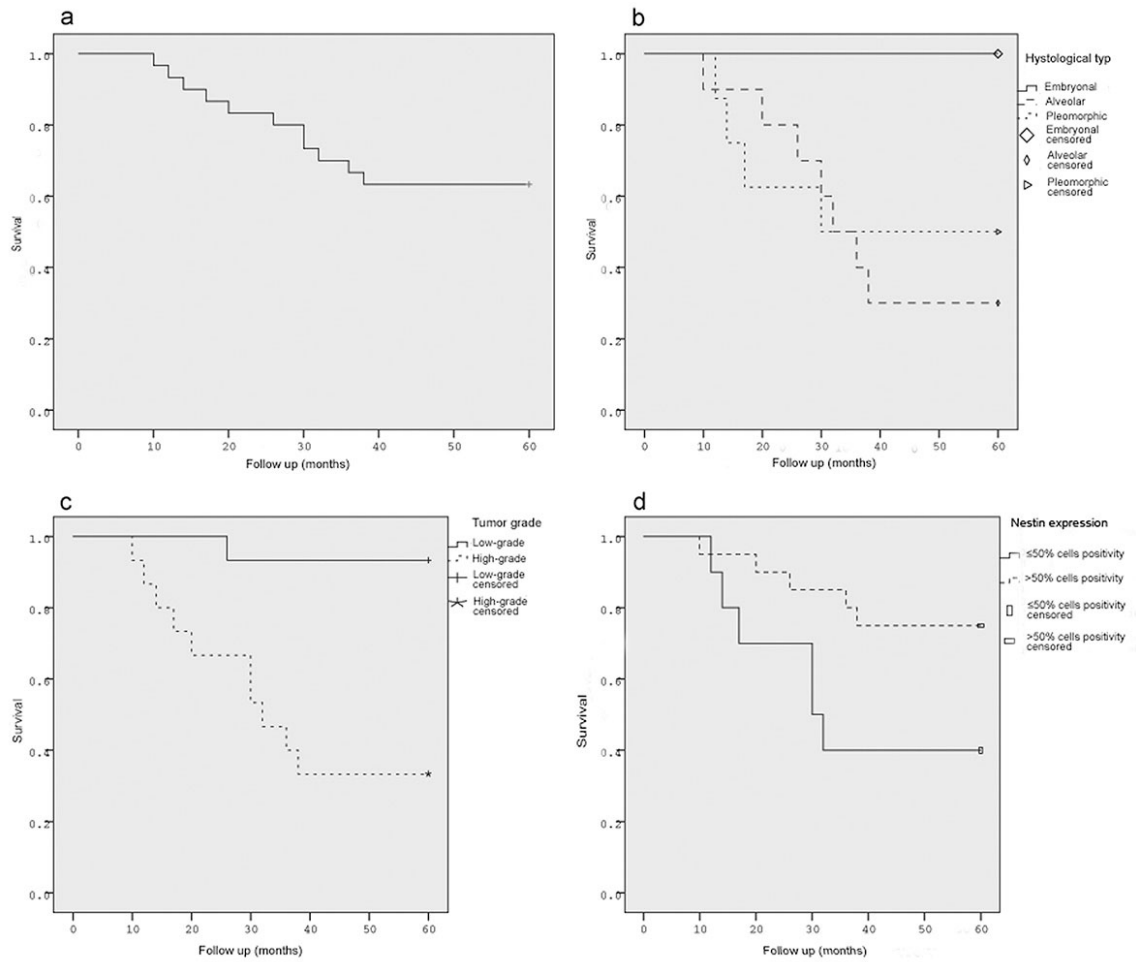

Figure 1. (a) Overall survival rate for all patients. Survival rate according to (b) histological subtype, (c) tumor grade, and (d) nestin protein expression.

\begin{tabular}{|c|c|c|c|c|c|c|}
\hline \multirow[t]{2}{*}{ Observed characteristics } & \multicolumn{5}{|c|}{ Overall survival (\%) } & \multirow[t]{2}{*}{$P$ value } \\
\hline & 1-year & 2-year & 3-year & 4-year & 5-year & \\
\hline \multicolumn{7}{|l|}{ Histological type } \\
\hline Embryonal & 100.0 & 100.0 & 100.0 & 100.0 & 100.0 & \multirow[t]{3}{*}{$0.004^{*}$} \\
\hline Alveolar & 90.0 & 80.0 & 40.0 & 30.0 & 30.0 & \\
\hline Pleomorphic & 87.5 & 62.5 & 50.0 & 50.0 & 50.0 & \\
\hline \multicolumn{7}{|l|}{ Grade } \\
\hline Low & 100.0 & 100.0 & 93.3 & 93.3 & 93.3 & \multirow[t]{2}{*}{$0.001^{*}$} \\
\hline High & 86.7 & 66.7 & 40.0 & 33.3 & 33.3 & \\
\hline \multicolumn{7}{|l|}{ Nestin } \\
\hline$\leq 50 \%$ positive cells & 90.0 & 70.0 & 40.0 & 40.0 & 40.0 & \multirow[t]{2}{*}{$0.044^{*}$} \\
\hline$>50 \%$ positive cells & 95.0 & 90.0 & 80.0 & 75.0 & 75.0 & \\
\hline
\end{tabular}

*Statistically significant, log-rank test. 
Histological tumor grade had a statistically significant effect on survival $(P=0.001$; Table 3 ). None of the subjects with low-grade tumors died during the first 2 years of follow-up (Figure 1). After 3 years, survival among this group of patients was $93.3 \%$, and remained at this level until the end of the observation period. In the high-grade tumor group, the survival rate was 86.7, 66.7, 40, 33.3, and 33.3\% after 1, 2, 3, 4, and 5 years, respectively (Figure 1).

\begin{tabular}{|c|c|c|c|c|}
\hline \multirow[t]{2}{*}{ Characteristic } & \multicolumn{2}{|c|}{ Univariate } & \multicolumn{2}{|c|}{ Multivariate } \\
\hline & $\operatorname{Exp}(B)^{\#}(95 \% C l)$ & $P$ value & $\operatorname{Exp}(\mathrm{B})(95 \% \mathrm{Cl})$ & $P$ value \\
\hline Gender & $0.607(0.161-2.290)$ & & - & \\
\hline Age & $1.039(1.014-1.063)$ & $0.002^{*}$ & $1.021(0.987-1.056)$ & 0.231 \\
\hline Primary site & $0.907(0.395-2.080)$ & 0.817 & - & - \\
\hline Histological type & $2.632(1.214-5.706)$ & $0.014^{*}$ & $1.573(0.477-5.188)$ & 0.457 \\
\hline Metastasis & $1.410(0.430-4.623)$ & 0.571 & - & - \\
\hline Tumor size & $2.349(0.507-10.886)$ & 0.926 & - & - \\
\hline Grade & $14.656(1.865-115.148)$ & $0.011^{*}$ & $4.013(0.219-73.536)$ & 0.349 \\
\hline Nestin expression & $0.314(0.095-1.038)$ & 0.058 & - & - \\
\hline
\end{tabular}

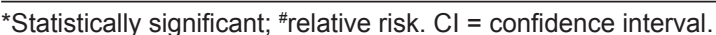

We observed that survival was significantly influenced by nestin protein expression $(P=0.044$; Table 2). Higher rates of survival were seen in the group with $>50 \%$ nestin-positive cells (Figures 1 and 2 ), with $95,90,80,75$, and $75 \%$ of such patients being alive after $1,2,3,4$, and 5 years, respectively. Survival of patients with $\leq 50 \%$ nestin-positive cells was $90 \%$ after 1 year, $70 \%$ after 2 years, and $40 \%$ after 3 , at which level this figure remained until the end of the investigation period.
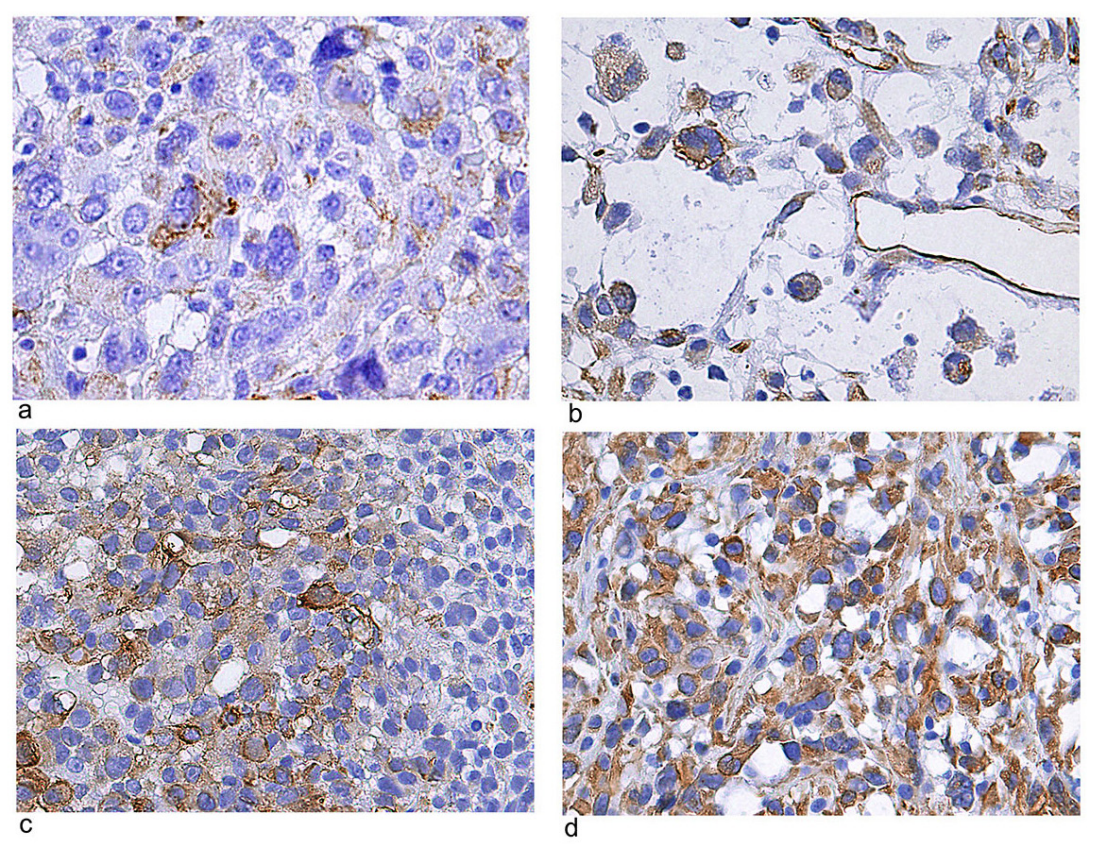

Figure 2. Immunohistochemical staining at $400 \mathrm{X}$ magnification. Nestin expression in $\leq 50 \%$ of tumor cells in (a) pleomorphic RMS, and $>50 \%$ of tumor cells in (b) embryonal RMS, and (c) and (d) alveolar RMS. 
Cox's univariate regression analysis showed that age, histological type, and grade significantly affected survival, while nestin expression demonstrated borderline significance $(P$ $=0.058$ ). However, multivariate Cox regression analysis did not identify any of these factors as predictors of survival (Table 3 ).

Table 4 shows the correlation of nestin expression and clinicopathological variables of the examined patients. The analysis showed statistical significance regarding the age of patients $(P=0.028)$ and the tumor grade $(P=0.022)$. The nestin expression in $>50 \%$ of tumor cells was associated with younger age and also with low grade RMS. There was no statistical association between the nestin expression and other parameters.

\begin{tabular}{|c|c|c|c|}
\hline \multirow[t]{2}{*}{ Characteristic } & \multicolumn{2}{|c|}{ Nestin expression } & \multirow[t]{2}{*}{$P$ value } \\
\hline & $\leq 50 \%$ positive cells & $>50 \%$ positive cells & \\
\hline \multicolumn{4}{|l|}{ Gender, N (\%) } \\
\hline Male & $8(42.1)$ & $11(57.9)$ & \multirow[t]{2}{*}{$0.246^{\mathrm{a}}$} \\
\hline Female & $2(18.2)$ & $9(81.8)$ & \\
\hline Age, years & $43.60 \pm 27.58$ & $21.92 \pm 22.23$ & $0.028^{\mathrm{b} *}$ \\
\hline \multicolumn{4}{|l|}{ Primary site, N (\%) } \\
\hline Upper extremity & $5(35.7)$ & $9(64.3)$ & \multirow[t]{3}{*}{$0.923^{\circ}$} \\
\hline Lower extremity & $4(33.3)$ & $8(66.7)$ & \\
\hline Trunk & $1(25)$ & $3(75)$ & \\
\hline \multicolumn{4}{|c|}{ Histological type, $N(\%)$} \\
\hline Embryonal & $2(16.7)$ & $10(83.3)$ & $0.100^{\circ}$ \\
\hline Alveolar & $3(30)$ & $7(70)$ & $0.406^{d}$ \\
\hline \multirow[t]{2}{*}{ Pleomorphic } & \multirow[t]{2}{*}{$5(62.5)$} & \multirow[t]{2}{*}{$3(37.5)$} & $0.062^{\mathrm{e}}$ \\
\hline & & & $0.342^{t}$ \\
\hline \multicolumn{4}{|c|}{ Metastatic disease, $\mathrm{N}(\%)$} \\
\hline Yes & $6(33.3)$ & $12(66.7)$ & \multirow[t]{2}{*}{$1.000^{\mathrm{a}}$} \\
\hline No & $4(33.3)$ & $8(66.7)$ & \\
\hline \multicolumn{4}{|l|}{ Tumor size, N (\%) } \\
\hline$\leq 5 \mathrm{~cm}$ & $3(33.3)$ & $6(66.7)$ & \multirow[t]{2}{*}{$1.000^{\mathrm{a}}$} \\
\hline$>5 \mathrm{~cm}$ & $7(33.3)$ & $14(66.7)$ & \\
\hline \multicolumn{4}{|l|}{ Grade, N (\%) } \\
\hline Low & $3(20)$ & $12(80)$ & \multirow[t]{2}{*}{$0.0220^{\mathrm{a}^{\mathrm{x}}}$} \\
\hline High & $7(46.7)$ & $8(53.3)$ & \\
\hline \multicolumn{4}{|l|}{ Vital status } \\
\hline Alive & $4(21)$ & $15(79)$ & \multirow{2}{*}{$0.108^{\mathrm{a}}$} \\
\hline Dead & $6(54.5)$ & $5(45.5)$ & \\
\hline
\end{tabular}

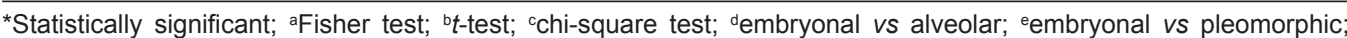
falveolar vs pleomorphic.

\section{DISCUSSION}

Soft tissue sarcomas account for less than $1 \%$ of all adult malignancies. Although infrequent in adults, RMS is a common childhood cancer, representing more than $50 \%$ of all soft tissue pediatric sarcomas (Ferrari et al., 2003; Sultan et al., 2009). Due to the rarity of adult RMS, information regarding its clinical and biological characteristics is very limited. Multiple adverse clinical factors appear to converge in patients with RMS, yet little is known about this disease.

Here, we studied a group of 30 patients with pathohistological diagnoses of RMS. We noticed that men were slightly overrepresented and that tumors $>5 \mathrm{~cm}$ were frequently observed (70\%). Nevertheless, primary tumor size $>5 \mathrm{~cm}$ did not significantly affect patient outcome. Upper extremities were the most common primary tumor sites, followed by the lower extremities and trunk, but this factor did not considerably affect OS. 
This study included adult and juvenile patients, the youngest being less than 1 year old and the oldest 77 years old. After the median follow-up period of 3.9 years, $63.3 \%$ were reported to be alive. As many other researchers have reported, better outcome was observed in the younger patient group (<18 years old), only one of whom died during the 5 years of follow-up. In contrast, of the older patients (>18 years old), 10/15 died in the same period (Hosoi et al., 2007; Sultan et al., 2009; Badr et al., 2012). The most likely reason for this is the fact that among younger patients, embryonal RMS was the most common diagnosis (80\%), while this histological type was not found in the older patient group (0.001). Adult RMS patients show a high incidence of pleomorphic and alveolar malignancies. Indeed, RMS histological type significantly differed with patient age ( $<0.001$; La Quaglia et al., 1994; Furlong and Fanburg-Smith, 2001; Allen et al., 2007; Stock et al., 2009).

In our study group, the most frequent histological type was embryonal, followed by alveolar, and pleomorphic (40, 33.3 and $26,7 \%$ respectively). The highest survival rate was seen in patients with the embryonal subtype, none of whom died during the follow-up period. A comparison of the histologic subtypes included revealed this difference to be statistically significant (Little et al., 2002; Dumont et al., 2013). There is conflicting evidence concerning the prognostic significance of histologic subtype (Crist et al., 1990; Crist et al., 2001; Hawkins et al., 2001). Although histology was found to be an important prognostic variable in the second IRS (Dumont et al., 2013), it was not included as an independent prognostic factor in IRS-IV (Crist et al., 1990; Crist et al., 2001).

Other lines of evidence suggest that histologic subtype may constitute an independent contributor to prognosis. An evaluation of 159 RMS patients treated at the National Cancer Institute over a 15-year period revealed a better outcome for embryonal RMS than identically treated alveolar or pleomorphic variants (Dagher and Helman, 1999; Raney et al., 2001; Company et al., 2011; Dumont et al., 2013). The results of our study are consistent with recent publications. As many other authors have reported, we have shown that both histologic subtype and tumor grade significantly correlate with patient prognosis (Tsokos et al., 1992; Ferrari et al., 2003; Company et al., 2011). The 5-year survival rate of patients suffering high-grade RMS was $33.3 \%$, significantly lower than that of those with low-grade RMS (93.3\%; P = 0.001; Furlong et al., 2001; Raney et al., 2010; Dumont et al., 2013).

The intermediate filament protein nestin, a well-known marker of neural progenitor cells, has been detected in a multitude of cellular phenotypes in embryonic and adult tissues. Although nestin is typically found in neural stem cells, it has also been observed in other cell and tissue types during mammalian embryogenesis, e.g. cardiac and skeletal muscles, umbilical cord blood, Sertoli and interstitial testicular cells, odontoblasts, hair follicle sheath cells, hepatic cells, and renal progenitors (Wiese et al., 2004; Krupkova et al., 2010).

In adults, nestin expression is not limited to the nervous system, appearing in healthy tissue, as well as during injuries or other pathological events. In general, the presence of nestin in the cells of adults indicates an undifferentiated state, plasticity, increased mobility, or pathological conditions (Krupkova et al., 2010). To date, numerous studies have shown that some cancer cells share many similar features with mammalian cells during embryogenesis. One such characteristic is the expression pattern of intermediate filament proteins such as nestin (Veselska et al., 2012). Nestin expression has been demonstrated in many types of malignancies of various origins (Krupkova et al., 2010). Furthermore, the occurrence of nestin-positive tumor cells has been associated with dedifferentiation and advanced grade in some cancers (Strojnik et al., 2007; Yang et al., 2008; Ishiwata et al., 2011; Wan et al., 2011; Skarda et al., 2012).

On the other hand, some clinical studies have demonstrated that nestin expression does not 
seem to be a powerful prognostic factor (Chinnaiyan et al., 2008; Kim et al., 2011; Lenz et al., 2011; Zambo et al., 2012). Many questions remain concerning the functional role and regulation of nestin expression in undifferentiated tissues, and the mechanisms relating to this in various solid tumors.

Our results showed that nestin expression significantly correlated with survival $(P=0.044)$. Specifically, a higher survival rate was observed in the group of cases showing nestin expression in $>50 \%$ of cells. When we analyzed nestin expression in relation to histological type, the majority of embryonal and alveolar RMS cases (83.3 and $70.0 \%$, respectively) demonstrated expression in more than $50 \%$ of tumor cells, while the majority of pleomorphic RMS cases $(62.5 \%)$ showed negative or focal expression. In addition, the extent of nestin expression was lower in high-grade than in low-grade RMS. Consistent with these results, we have shown that older RMS patients exhibited negative expression more often than younger patients, and this result was statistically significant $(P=0.028)$. Our findings might be explained by the fact that we did not analyze morphological subtypes of RMS, owing to the small number of patients included. RMS comprises a group of morphologically similar but biologically diverse lesions. For example, embryonal RMS was the most common type in our study, but its pattern of development is highly variable, ranging from poorly to well-differentiated tumors (Furlong and Fanburg-Smith, 2001; Parham et al., 2013).

Of the few studies to date that have analyzed nestin expression in RMS, all have reported strong expression in the majority of embryonal and alveolar cases (Kobayashi et al., 1998; Shimada et al., 2007; Sadikovic et al., 2011; Sana et al., 2011). However, none have investigated nestin expression in pleomorphic RMS. In addition, these studies did not examine the correlation between nestin expression and established prognostic factors (such as primary site, tumor size, distant metastases, age at diagnosis, and histology), nor its association with survival.

\section{CONCLUSION}

Nestin overexpression was observed in most embryonal RMS cases, low-grade tumors, in early stages of the disease, and among younger sufferers. Our results lead us to propose nestin expression as a possible positive prognostic factor in RMS.

\section{Conflicts of interest}

The authors declare no conflict of interest.

\section{ACKNOWLEDGMENTS}

Research supported by the following grant: III 41027 from the Ministry of Education, Science and Technological Development of the Republic of Serbia.

\section{REFERENCES}

Allen SD, Moskovic EC, Fisher C and Thomas JM (2007). Adult rhabdomyosarcoma: cross-sectional imaging findings including histopathologic correlation. AJR Am. J. Roentgenol. 189: 371-377.

Almeida PS, Manoel WJ, Reis AA, Silva ER, et al. (2008). TP53 codon 72 polymorphism in adult soft tissue sarcomas. Genet. Mol. Res. 7: 1344-1352.

Badr MA, Al-Tonbary YA, Mansour AK, Hassan TH, et al. (2012). Epidemiological characteristics and survival studies of rhabdomyosarcoma in East Egypt: a five-year multicenter study. ISRN Oncol. 2012: 674523. 
Chinnaiyan P, Wang M, Rojiani AM, Tofilon PJ, et al. (2008). The prognostic value of nestin expression in newly diagnosed glioblastoma: report from the Radiation Therapy Oncology Group. Radiat. Oncol. 3: 32.

Company F, Pedram M and Rezaei N (2011). Clinical characteristics and the prognosis of childhood rhabdomyosarcoma in 60 patients treated at a single institute. Acta Med. Iran 49: 219-224.

Crist WM, Garnsey L, Beltangady MS, Gehan E, et al. (1990). Prognosis in children with rhabdomyosarcoma: a report of the intergroup rhabdomyosarcoma studies I and II. Intergroup Rhabdomyosarcoma Committee. J. Clin. Oncol. 8: 443-452.

Crist WM, Anderson JR, Meza JL, Fryer C, et al. (2001). Intergroup rhabdomyosarcoma study-IV: results for patients with nonmetastatic disease. J. Clin. Oncol. 19: 3091-3102.

Dagher R and Helman L (1999). Rhabdomyosarcoma: an overview. Oncologist 4: 34-44.

Dasgupta R and Rodeberg DA (2012). Update on rhabdomyosarcoma. Semin. Pediatr. Surg. 21: 68-78.

Dumont SN, Araujo DM, Munsell MF, Salganick JA, et al. (2013). Management and outcome of 239 adolescent and adult rhabdomyosarcoma patients. Cancer Med. 2: 553-563.

Ferrari A, Dileo P, Casanova M, Bertulli R, et al. (2003). Rhabdomyosarcoma in adults. A retrospective analysis of 171 patients treated at a single institution. Cancer 98: 571-580.

Furlong MA and Fanburg-Smith JC (2001). Pleomorphic rhabdomyosarcoma in children: four cases in the pediatric age group. Ann. Diagn. Pathol. 5: 199-206.

Furlong MA, Mentzel T and Fanburg-Smith JC (2001). Pleomorphic rhabdomyosarcoma in adults: a clinicopathologic study of 38 cases with emphasis on morphologic variants and recent skeletal muscle-specific markers. Mod. Pathol. 14: 595-603.

Hawkins WG, Hoos A, Antonescu CR, Urist MJ, et al. (2001). Clinicopathologic analysis of patients with adult rhabdomyosarcoma. Cancer 91: 794-803.

Hosoi H, Teramukai S, Matsumoto Y, Tsuchiya K, et al. (2007). A review of 331 rhabdomyosarcoma cases in patients treated between 1991 and 2002 in Japan. Int. J. Clin. Oncol. 12: 137-145.

Ishiwata T, Matsuda $Y$ and Naito $Z$ (2011). Nestin in gastrointestinal and other cancers: effects on cells and tumor angiogenesis. World J. Gastroenterol. 17: 409-418.

Kim KJ, Lee KH, Kim HS, Moon KS, et al. (2011). The presence of stem cell marker-expressing cells is not prognostically significant in glioblastomas. Neuropathology 31: 494-502.

Kobayashi M, Sjöberg G, Söderhäll S, Lendahl U, et al. (1998). Pediatric rhabdomyosarcomas express the intermediate filament nestin. Pediatr. Res. 43: 386-392.

Krupkova O Jr, Loja T, Zambo I and Veselska R (2010). Nestin expression in human tumors and tumor cell lines. Neoplasma 57: 291-298.

La Quaglia MP, Heller G, Ghavimi F, Casper ES, et al. (1994). The effect of age at diagnosis on outcome in rhabdomyosarcoma. Cancer 73: 109-117.

Lendahl U, Zimmerman LB and McKay RD (1990). CNS stem cells express a new class of intermediate filament protein. Cell 60: 585-595.

Lenz J, Karasek P, Jarkovsky J, Muckova K, et al. (2011). Clinicopathological correlations of nestin expression in surgically resectable pancreatic cancer including an analysis of perineural invasion. J. Gastrointestin. Liver Dis. 20: 389-396.

Little DJ, Ballo MT, Zagars GK, Pisters PW, et al. (2002). Adult rhabdomyosarcoma: outcome following multimodality treatment. Cancer 95: 377-388.

Meza JL, Anderson J, Pappo AS, Meyer WH, et al. (2006). Analysis of prognostic factors in patients with nonmetastatic rhabdomyosarcoma treated on intergroup rhabdomyosarcoma studies III and IV: the Children's Oncology Group. J. Clin. Oncol. 24: 3844-3851.

Newton WA Jr, Gehan EA, Webber BL, Marsden HB, et al. (1995). Classification of rhabdomyosarcomas and related sarcomas. Pathologic aspects and proposal for a new classification-an Intergroup Rhabdomyosarcoma Study. Cancer 76: 1073-1085.

Pallari HM, Lindqvist J, Torvaldson E, Ferraris SE, et al. (2011). Nestin as a regulator of Cdk5 in differentiating myoblasts. Mol. Biol. Cell 22: 1539-1549.

Parham DM, Barr FG, Montgomery EA and Nascimento AF (2013). Skeletal-muscle tumours. In: WHO Classification of Tumours of Soft Tissue and Bone (Fletcher C, Bridge JA, Hogendoorn P and Mertens F, eds.). IARC, Lyon, 127-134.

Raney RB, Maurer HM, Anderson JR, Andrassy RJ, et al. (2001). The Intergroup Rhabdomyosarcoma Study Group (IRSG): major lessons from the IRS-I through IRS-IV studies as background for the current IRS-V treatment protocols. Sarcoma 5: 9-15.

Raney RB, Anderson JR, Brown KL, Huh WW, et al. (2010). Treatment results for patients with localized, completely resected (Group I) alveolar rhabdomyosarcoma on Intergroup Rhabdomyosarcoma Study Group (IRSG) protocols III and IV, 19841997: a report from the Children's Oncology Group. Pediatr. Blood Cancer 55: 612-616.

Sadikovic B, Graham C, Ho M, Zielenska M, et al. (2011). Immunohistochemical expression and cluster analysis of mesenchymal and neural stem cell-associated proteins in pediatric soft tissue sarcomas. Pediatr. Dev. Pathol. 14: 259-272. 
Sana J, Zambo I, Skoda J, Neradil J, et al. (2011). CD133 expression and identification of CD133/nestin positive cells in rhabdomyosarcomas and rhabdomyosarcoma cell lines. Anal. Cell. Pathol. 34: 303-318.

Shimada S, Tsuzuki T, Kuroda M, Nagasaka T, et al. (2007). Nestin expression as a new marker in malignant peripheral nerve sheath tumors. Pathol. Int. 57: 60-67.

Skarda J, Kolar Z, Janikova M, Radova L, et al. (2012). Analysis of the prognostic impact of nestin expression in non-small cell lung cancer. Biomed. Pap. Med. Fac. Univ. Palacký Olomouc Czech Repub. 156: 135-142.

Stock N, Chibon F, Binh MB, Terrier P, et al. (2009). Adult-type rhabdomyosarcoma: analysis of 57 cases with clinicopathologic description, identification of 3 morphologic patterns and prognosis. Am. J. Surg. Pathol. 33: 1850-1859.

Strojnik T, Røsland GV, Sakariassen PO, Kavalar R, et al. (2007). Neural stem cell markers, nestin and musashi proteins, in the progression of human glioma: correlation of nestin with prognosis of patient survival. Surg. Neurol. 68: 133-143.

Sultan I, Qaddoumi I, Yaser S, Rodriguez-Galindo C, et al. (2009). Comparing adult and pediatric rhabdomyosarcoma in the surveillance, epidemiology and end results program, 1973 to 2005: an analysis of 2,600 patients. J. Clin. Oncol. 27: 3391-3397.

Tsokos M, Webber BL, Parham DM, Wesley RA, et al. (1992). Rhabdomyosarcoma. A new classification scheme related to prognosis. Arch. Pathol. Lab. Med. 116: 847-855.

Veselska R, Skoda J and Neradil J (2012). Detection of cancer stem cell markers in sarcomas. Klin. Onkol. 25 (Suppl 2): S16-S20.

Wan F, Herold-Mende C, Campos B, Centner FS, et al. (2011). Association of stem cell-related markers and survival in astrocytic gliomas. Biomarkers 16: 136-143.

Wiese C, Rolletschek A, Kania G, Blyszczuk P, et al. (2004). Nestin expression-a property of multi-lineage progenitor cells? Cell. Mol. Life Sci. 61: 2510-2522.

Yang XH, Wu QL, Yu XB, Xu CX, et al. (2008). Nestin expression in different tumours and its relevance to malignant grade. J. Clin. Pathol. 61: 467-473

Zambo I, Hermanova M, Adamkova Krakorova D, Mudry P, et al. (2012). Nestin expression in high-grade osteosarcomas and its clinical significance. Oncol. Rep. 27: 1592-1598. 